

\title{
"Sorry You Are Not Fit to be a Doctor": Do We Need to Penalise Unwell Medical Trainees?
}

\author{
Fahisham Taib, Hans Van Rostenberghe, Azizah Othman \\ Pediatrics Department, School of Medical Sciences, Universiti Sains \\ Malaysia, Kelantan, MALAYSIA
}

To cite this article: Taib F, Van Rostenberghe H, Othman A. "Sorry you are not fit to be a doctor": do we need to penalise unwell medical trainees? Education in Medicine Journal. 2020;12(1): 65-69. https://doi.org/10.21315/eimj2020.12.1.7

To link to this article: https://doi.org/10.21315/eimj2020.12.1.7

\begin{abstract}
Unwell medical students and trainees may pose significant medical risks to the patients and ethical challenge for colleagues, clinical supervisors and governing institutions. Medical students who suffer from medical or psychological illnesses, which directly affect their function, may deem hazardous for the safety of the patients. Fitness to practice is crucial element in decision-making, to prevent potential fatal consequences of students' action. We presented a case of a determined medical student who was diagnosed with epilepsy, complicated with unresolved post-traumatic stress symptoms from his dark teenager years. He struggled academically during his training as a doctor. There are many ethical questions regarding his fitness to practice at this stage and the need for supportive measures following the completion of his medical training. Maintaining his individual confidentiality and rights are discussed here, tailoring to the potential benefits and harms. Managing ethically challenged and sick medical students involve compassion, non-stigmatised and sound moral judgement in order to resolve future shortcomings according to Malaysian context.
\end{abstract}

Keywords: Fitness to practice, Medical trainee, Ethics, Medical illness, Mental illness

Fahisham Taib, Pediatrics Department, School of Medical Sciences, Universiti Sains Malaysia, 16150 Kubang Kerian, Kelantan, Malaysia | Email: fahisham@gmail.com

\section{INTRODUCTION}

Many young people dream of becoming a pilot. There is a long list of predefined medical conditions that are incompatible with the profession of a pilot (1). Candidates, students or pilots with any of these conditions, have no choice but to give up their dream notwithstanding of the stage of training or professional achievement. Just as pilots, medical doctors do have a huge professional responsibility towards the society. Medical errors executed by doctors can have dire consequences for the life of others. There are international guidelines available to manage professional conduct of the doctors and even medical students (2), but rather unclear for those in Malaysia. Medical students are not subjected to the regulation imposed by medical council until after their graduation. The decision on the students' fitness is based on medical school's assessment and health probability at that point of time. There is no available standard operational procedure to limit career progression (in Malaysian context) 
for a sick medical student as they have yet to graduate and this does not fall within the medical council jurisdiction (3). However, these students should voluntarily declare their fitness to practice prior to registration and even before enrolling into medical schools. Various career options (e.g., careers in the pharmaceutical industry, laboratory based careers, public health or management based careers) are available where patients' safety is not directly impacted by the illness of future doctors and this should be discussed to change their perception and career direction.

We presented the case of a medical trainee, who was diagnosed with epilepsy and on the background of early childhood traumatic experience. He wanted to pursue his medical training despite concern of his medical fitness, scepticism on his competency, safety and function as a junior doctor in the future. Should the medical school allow him to achieve his dream to becoming a doctor? Is it justifiable to stop his study due to potential future harm caused by him to his patients? Should the medical school recommend him to safely practice as medical practitioner after passing his final medical exam?

\section{THE CASE}

A final year medical student was referred for medical assessment following his failure to complete his medical rotation. A detail history suggested that he was a bright and enthusiastic student, accomplished good academic merit from a renowned boarding school, prior to entering the medical study. $\mathrm{He}$ started to have repeated absences in his pre-clinical year due to frequent fainting episodes of unknown aetiology. $\mathrm{He}$ was initially diagnosed as conversion disorder following a review by the psychiatrist. This has affected his performance in his firstyear medical exam. He struggled during his clinical placement with increasing anxiety symptoms, depressed mood, selfharm and suicidal ideation. Epilepsy was diagnosed following a thorough medical and psychological assessment. $\mathrm{He}$ was treated with an anti-epileptic drug (AED). Psychological assessment revealed his posttraumatic stress disorder from his traumatic childhood experience, resulted in moderate level of depression and anxiety. The maladaptive coping, continuous stressors and demands of clinical training have triggered serial exacerbation of his symptoms. $\mathrm{He}$ eventually accepted his medical diagnosis and working towards complying with his medical management. He appeared psychologically fatigue but persevere on his main goal which was to achieve his childhood dream as a practicing doctor.

\section{DISCUSSION}

Most budding doctors believe that hard work, sweat and dedication would lead to successful careers. Unfortunately, many of trainees experience medical and mental health problems which becoming more apparent and overwhelming following the demand of clinical training. In our scenario, the student was diagnosed with partiallycontrolled seizure, on the background of traumatic life experience and psychological issue. Mental health represents a significant burden to the suffering student and can negatively affect the quality of life and safety outcomes. The complexity of his medical condition and psychosocial needs lead to a collective approach to this case. The decision to limit his career progression may need to be revisited carefully.

\section{Identifying IIIness}

The first step in this process is the assessment and evaluation of student's ability to function with the medication. Certain medical conditions are remediable and controlled using appropriate drugs. Diagnosis of the underlying condition is vital and should be made by a senior person due to legal impact of the decision and for optimisation of his symptom. Few scenarios can be derived from here:

a. If the student has a medical illness, he should be given time to recover to his 
baseline function. Premature decision on his clinical status may not be appropriate. Control of symptoms may be achieved from holistic approach on the case and optimisation of his medication.

b. If the medical condition is uncontrolled, the best way forward is to individualised the approach. A physically disabled student may work in academia, community work or area which would allow his maximum ability.

c. If the medical illness potentially life threatening, effort should be made to follow student's wishes as per palliative patient. This should be tailored according to need and requirement.

d. If the student develops mental and psychological illnesses, determination on curative certainty can be difficult. The approach should focus on the improvement on the quality of life.

Medical students have high rates of maladaptive perfectionism, characterised by unrealistic, unattainable, or unsustainable standards of accomplishment (4). They are vulnerable to factors that can worsen their medical illnesses, if diagnosed. Allowing students' recovery time is vital although the future outcome is impossible to predict. Potential triggers of his stress should be prevented. The supervisor is morally obliged to inform on career choice at that stage, and the feasibility to achieve different goals in life. Discussion on future career pathway should be initiated early to allow insightful decision making. Medical schools need to devise an exit strategy for the student's career progress, for example, diverting students to a specialty which is less stressful such as medical education, research, informatics and even medical writing (3). Successful completion of his degree indirectly helps his self-confidence, self-awareness and resilience.

Having a complex case like this requires a specialised committee discussion. Documentation on student's impaired behaviour is important for local support and corrective action. In a low risk case, review is done by the committee on a regular basis. In a high risk case, collective evaluation between the specialist involved and the hospital management authority is required. Assessment of the student should be completed at each crisis points. However, predicting future functioning of the student would be remotely impossible. The judgement taken at that point of time should be based on recommendation of the senior supervisors, evidence of the non-functionality of his health status and his psychosocial dynamic.

If problem truly lies on the ongoing medical ground, channeling the student to appropriate field would allow adjustment phase and deem appropriate. He has to be allowed to make an informed decision based on his best interest and choice. University has the duty to ensure students produced are able to practice high-quality of medicine for the patients that they are cared for. Doctors are required to recognise the possible impairment of their colleagues. Similar to this case, his peers have the obligation and reponsibility to disclose information to the governing authority regarding his ill health issue. However, revealing such information may lead to stigmatisation as a sick person, considered "weak" or out of depth for the involved student. These perceptions and apparent discrimination are likely to play in student's reluctance to seek help for his health-related conditions (5). Stress including heavy workload, sleep deprivation, relocation issues, poor learning environments, family issues, debt and feelings of inadequacy provokes burnout and compassion fatigue (4). It affects emotional, physical and spiritual depletion when caring for patients which leads to a series of poor performance outcome (6). Student should develop "selfcare" ability to allow a positive outcome on his health.

\section{Is There a Way Out?}

There are many conflicting ethical duties in such case. Firstly, confidentiality of the student involved should be maintained. 
Using ethical principle of non-maleficence (do not harm), reporting of student's ailment is necessary to protect the general public interest. This information must be kept confidential as part of respecting his autonomy. At the same time, disclosing medical illness should be based on his best interest, which is bound by the principle of beneficence (do good). Student should receive treatment according to his needs and underlying problems to allow a fair chance of recovery.

Secondly, reporting student's illness to the medical school may deprive him from becoming a medical doctor. Whilst this decision is bound by the probability of his future outcome, our judgement should focus on the primary duty to care and to protect the society from serious consequences. The relevant drive for disclosure of information must be in parallel to the public interest. Consent for the voluntary disclosure should be obtained (7). However, student with mental illness may pose an extra challenge. He should have insight of his needs for help and searching for appropriate guidance. The conceptual framework of bioethics has accorded paramount status to the valuecomplex of individualism, underscoring the principles of individual rights, autonomy, self-determination and their legal expression in the jurisprudential notion of privacy (8). It is morally required for a person to assume responsibility for his choices, actions and decisions to act on the basis of informed reason and autonomously held.

Thirdly, medical institution should have compassion for the demise of this student. Decision made may have longterm consequences for his future career. Compassion is a form of love that needs critical reflection; but nevertheless has an enormous power to humanise (9). It offers the opportunity to acknowledge of the student's suffering. A bilateral relationship only works when trust is present. Clinical judgement in a "paternalistic" way potentially may end up in catastrophe. As a future healthcare professional, he should act rightly to enable him to live an exemplary human life; displaying conscience, wisdom, temperance, courage, integrity, self-knowledge, justice and capacity for friendship. This is called virtue ethic which emphasises on the character of oneself as to assimilate principles, rules and duties, as well as the consequences of his performance or non-performance (10). Mutual decision must come from both side; the governing body to show some form of compassion and the student to have a sound ethical principle behind all his actions.

Unfortunately, the culture in medicine has placed a low priority on student's mental or physical health. Often the focus would be to ensure that the trainee can function well when entering the medical profession. Protecting patients from the damages caused by unwell medical personnel is the central reason for wrongly dismissal without considering of other factors. Initiatives should be made to encourage student to seek help early, thus avoiding suspicion between the colleagues, trainers and eroding trust with the public.

\section{CONCLUSION}

Empathetic and healing relationships are vital rather than suspicion and hatred when dealing with the unwell student. Stigma of being unwell, medication dependent or label such as mental illness, should be quashed (11). The student need help in his journey to recover, with appropriate direction for his future. Student should be supported to find his realistic career pathway if needed, and future result of his medical illness should not be the fulcrum for a definite expulsion from medicine. Deficient of professional performance should not be an obstacle for impairment of fitness to practice, but debate on the appropriate resolution should be allowed with confidentiality, under the medical school academic procedures. 


\section{REFERENCES}

1. Houston S. Aviation medical exams: disqualifying medical conditions. 2019 [cited 20 Sept 2019]. Available at: https:// www.thebalancecareers.com/aviationmedical-exams-disqualifying-medicalconditions- 282925

2. General Medical Council. Professional behaviour and fitness to practice: guidance for medical schools and their students. Manchester: General Medical Council; 2016. p. 13-4.

3. Abdullah MD, Ahmad Fuad AF, Rahman HI, Min MTK. Fitness to practise for doctors and medical students with mental issues in Malaysia. Journal of Clinical and Health Sciences. 2019; 4(1):22-9. https:// doi.org/10.24191/jchs.v4i1.7279

4. Konopasek L, Slavin S. Addressing resident and fellow mental health and well-being: what can you do in your department? J Pediatr. 2015;167:1183-4. https://doi.org/ 10.1016/j.jpeds.2015.09.037

5. Hendin H, Reynolds C, Fox D, Altchuler SI, Rodgers P, Rothstein L, et al. Licensing and physician mental health: problems and possibilities. Journal of Medical Licensure and Discipline. 2007;93(2):6-11.
6. Hassan TB. Averting compassion fatigue and burnout. Who should help us conquer our demons? Emerg Med J. 2015;32(8):586-7. https://doi.org/10.1136/ emermed-2015-204752

7. Wareham C. Confidentiality and fitness to drive: professional, ethical, and legal duties in the case of the diabetic bus driver. S Afr Med J. 2017;107(8):684-6. https://doi .org/10.7196/SAMJ.2017.v107i8.12412

8. Stirrat GM, Gill R. Autonomy in medical ethics after O'Neill. J Med Ethics. 2005;31(3):127-30. https://doi.org/10.1136/ jme.2004.008292

9. Bolsin S, Faunce T, Oak J. Practical virtue ethics: healthcare whistleblowing and portable digital technology. J Med Ethics. 2005;31(10):612-8. https://doi.org/10.1136/ jme.2004.010603

10. van der Cingel M. Compassion and professional care: exploring the domain. Nurs Philos. 2009;10(2):124-36. https://doi .org/10.1111/j.1466-769X.2009.00397.x

11. Vonnegut M. Recovery and service: on being a physician with mental illness. AMA J Ethics. 2016;18(6):643-5. https://doi.org/10.1001/journalofethics .2016.18.6.mnar1-1606 